BOMB CHILDREN 
This page intentionally left blank 


\section{BOMB CHILDREN}

Life in the Former Battlefields of Laos

LEAH ZANI

Duke University Press · Durham and London · 2019 
(C) 2019 Duke University Press

All rights reserved

Printed in the United States of America on acid-free paper $\infty$ Designed by Courtney Leigh Baker and typeset in Whitman and

Rockwell by Westchester Publishing Services

Library of Congress Cataloging-in-Publication Data

Names: Zani, Leah, [date] author.

Title: Bomb children : life in the former battlefields of Laos / Leah Zani.

Description: Durham : Duke University Press, 2019. |

Includes bibliographical references and index.

Identifiers: LCCN 2018052743 (print)

LCCN 2019010347 (ebook)

ISBN 9781478005261 (ebook)

IS BN 9781478004226 (hardcover : alk. paper)

ISBN 9781478004851 (pbk. : alk. paper)

Subjects: LCSH: Vietnam War, 1961-1975-Campaigns-Laos. |

Vietnam War, 1961-1975-Aerial operations, American. |

Laos-History-1975- | Unexploded ordnance-

Social aspects_Laos. | Cluster bombs_Laos. |

Land mine victims-Laos. | Ethnology-Laos. |

Laos-Rural conditions-Poetry.

Classification: LCC DS557.8.L3 (ebook)

LCC DS557.8.L3 Z36 2019 (print) |

DDC $959.704 / 31-\mathrm{dc} 23$

LC record available at https://lccn.loc.gov/2018052743

Cover art: Cluster munitions, cope Centre, Vientiane, Laos.

(c) Godong/Alamy Stock Photo. 